\title{
Management of Refractory Breathlessness: a Review for General Internists
}

\author{
Annie Massart, $M D^{1,2}$ (1) and Daniel P. Hunt, $M D^{7}$ \\ 'Division of Hospital Medicine, Emory University School of Medicine, Atlanta, GA, USA; ${ }^{2}$ Atlanta, USA.
}

Internists frequently care for patients who suffer from breathlessness in both the inpatient and the outpatient settings. Patients may experience chronic refractory breathlessness despite thorough evaluation and management of their underlying medical illnesses. Left unmanaged, chronic breathlessness is associated with worsened quality of life, more frequent visits to the emergency room, and decreased activity levels, as well as increased levels of depression and anxiety. This narrative review summarizes recent research on interventions for the relief of breathlessness, including both non-pharmacologic and pharmacologic options.

KEY WORDS: dyspnea; breathlessness; chronic disease management.

J Gen Intern Med 36(4):1035-40

DOI: $10.1007 / \mathrm{s} 11606-020-06439-0$

(C) Society of General Internal Medicine 2021

$\mathrm{D}$ yspnea, or breathlessness, is defined as "a subjective experience of breathing discomfort that consists of qualitatively distinct sensations that vary in intensity." "Distinct sensations that patients experience may be categorized as work or effort of breathing, chest tightness, and air hunger or unsatisfied inspiration. ${ }^{2}$ Breathlessness is a common symptom for patients in both the inpatient and the outpatient settings. Large community surveys estimate that $25 \%$ of community-dwelling adults older than 70 experience dyspnea with some regularity ${ }^{3}$ while $9-11 \%$ of community-dwelling adults experience chronic, refractory breathlessness. ${ }^{4,5}$ Chronic breathlessness is defined as breathlessness at rest or that limits activities despite optimal medical management of the underlying disease process. ${ }^{6}$ The prevalence of refractory breathlessness increases with increasing level of medical care, patient age, and stage of illness. A cross-sectional population-based survey study of 1404 randomly selected patients 70 years old or older found that the prevalence of breathlessness increased with advancing age with $32.3 \%$ of all subjects over the age of 70 and $45.3 \%$ of men and $41.8 \%$ of women over the age of 80 experiencing this symptom. ${ }^{7}$ A study of patients with chronic lung disease or lung cancer found that breathlessness occurred

Received April 24, 2020

Accepted December 10, 2020

Published online January 19, 2021 in $94 \%$ and $78 \%$ respectively during the final year of life. ${ }^{8}$ The presence of chronic breathlessness portends higher risk of mortality in patients with COPD and heart disease, and in the elderly. ${ }^{9}$

Despite being a common concern for patients, chronic breathlessness is under-recognized by clinicians. ${ }^{10}$ Left unmanaged, chronic dyspnea can have profound impacts on patients including worsened quality of life, more frequent visits to the emergency room, decreased activity levels, increased social isolation, and worsened family well-being. ${ }^{6,11-13}$ For older patients with COPD, chronic dyspnea is one of the most important factors limiting the ability to complete daily activities. ${ }^{14}$ Chronic dyspnea is also associated with increased levels of depression, anxiety, and spiritual distress. ${ }^{6,13}$

The first step in dyspnea management is to evaluate for the underlying medical etiology and initiate appropriate diseasetargeting therapies. Pulmonary or cardiac disease processes are the most common causes of chronic dyspnea, although other conditions may also present with chronic breathlessness (Table 1). An understanding of the physiologic mechanisms that result in the sensation of breathlessness is helpful for determining potential causes and for management of the symptom itself.

\section{BIOLOGY OF BREATHLESSNESS}

Although breathlessness may result from a diverse group of disease states, it always reflects a disruption in the balance between inspiratory drive and ventilatory capacity. ${ }^{12}$ The somatosensory cortex integrates data about the inspiratory drive from the medullary respiratory centers as well as information about respiratory function from chemoreceptors (which detect variations in $\mathrm{pO}_{2}$ and $\mathrm{pCO}_{2}$ ) and peripheral mechanoreceptors in the lungs and respiratory muscles (which detect stretch or motor activity). ${ }^{15}$ In healthy individuals, as inspiratory drive intensifies (such as during exercise), medullary respiratory centers relay this heightened need to both the respiratory muscles as well as a corollary message to the somatosensory cortex. Ventilation increases and the degree of augmented activity is relayed via the peripheral mechanoreceptors to the somatosensory cortex. ${ }^{1}$ The somatosensory cortex interprets this as equipoise between respiratory drive and performance so there is no associated discomfort. For patients with breathlessness, the respiratory drive from the medullary centers is 
Table 1 Causes of Chronic Refractory Breathlessness

\begin{tabular}{ll}
\hline \hline Pulmonary & Chronic obstructive pulmonary disease \\
Bronchiectasis \\
Asthma \\
Tracheomalacia \\
Interstitial lung disease \\
Cancer \\
Chronic pulmonary embolic disease \\
Pulmonary hypertension \\
Vasculitis \\
Pleural effusion \\
Heart failure \\
Ischemic heart disease \\
Arrhythmia \\
Valvular heart disease \\
Constrictive pericarditis \\
Cardiac & Amyotrophic lateral sclerosis \\
& Myasthenia gravis \\
Guillain-Barre syndrome \\
Chest wall deformities \\
Upper airway compression \\
Vocal cord dysfunction \\
Obesity \\
Deconditioning \\
Anemia \\
Anxiety \\
\hline
\end{tabular}

inadequately addressed. This may be secondary to triggers for increasing respiratory drive (i.e., hypercapnia, hypoxia, acidosis) and/or due to a decline in pulmonary function or worsening muscle weakness. ${ }^{1}$ The peripheral chemoreceptors and/or mechanoreceptors send afferent inputs back to the somatosensory cortex reflecting this underperformance. The somatosensory cortex perceives this unmet need as respiratory discomfort. ${ }^{1}$

In addition to the physical sensation of breathlessness, there is a significant affective component for many patients. Studies using functional magnetic resonance imaging (fMRI) demonstrate that inducing dyspnea leads to activation of the limbic and paralimbic systems which can result in anxiety, panic, and affective distress. ${ }^{16}$ These emotional centers are activated by the anticipation of dyspnea as well, providing further evidence for the role of affective processing for influencing patient experiences. ${ }^{16}$ As a result, patients with comparable severity of pulmonary dysfunction may describe very different degrees of dyspnea. ${ }^{17}$

The affective processing of dyspnea impacts the approach to this symptom in the broader context of patients' quality of life. As aforementioned, patients with chronic dyspnea have higher rates of depression and anxiety. ${ }^{6}$ Conversely, uncontrolled anxiety can worsen dyspnea. ${ }^{18}$ The American Thoracic Society guidelines on assessing and managing dyspnea recommend considering distinct domains: sensory-perceptual experience, affective distress, and symptom/disease impact or burden. ${ }^{1}$ When treating patients with refractory breathlessness, it is helpful to keep these distinct components in mind as each can drive dyspnea alone or they may also work in concert to exacerbate this symptom. Recognizing this dynamic will allow clinicians to provide better symptom control as well as education for patients to help them better understand their symptoms.

\section{EVALUATION OF BREATHLESSNESS}

Chronic refractory breathlessness may be the consequence of a range of diseases (see Table 1) and requires thoughtful evaluation that begins with the history and physical exam. Similarly to obtaining a detailed description of pain, eliciting details about the character of dyspnea is useful in considering the differential diagnosis, workup, and treatment options. The Multidimensional Dyspnea Profile provides a framework for assessment of breathlessness that includes the degree of unpleasantness or discomfort of breathing sensations (ranging from 0 to 10 where 0 is no discomfort to 10 indicating unbearable), sensory quality (effort, air hunger, tightness, mental effort, breathing a lot), and intensity of negative emotions (depressed, anxious, frustrated, angry, afraid). ${ }^{2,19}$ See Table 2 for a summary of common patient descriptors of breathlessness. A study of inpatients with significant dyspnea found the most common description was "air hunger" and associated emotional symptoms were anxiety and frustration. ${ }^{2}$ Among patients presenting to an outpatient pulmonary clinic, patients' qualities of breathlessness varied depending on the underlying illness. ${ }^{19}$ Another study of 148 outpatients found that "chest tightness" was associated with asthma and was much less common as a descriptor among patients with $\mathrm{COPD}^{20}$ This finding may be useful in differentiating between these conditions. In addition, "shallow breathing" was associated with interstitial lung disease.

Associated symptoms are also useful in narrowing the differential diagnosis for chronic breathlessness. ${ }^{21}$ The absence of cough argues against COPD. Absence of throat

Table 2 Patient Descriptions of Breathlessness (Derived from Mahler, Am J Resp Crit Care Med, 1996)

\begin{tabular}{|c|c|c|}
\hline Characteristic & $\begin{array}{l}\text { Patient } \\
\text { description }\end{array}$ & Associated conditions \\
\hline $\begin{array}{l}\text { Work/effort of } \\
\text { breathing }\end{array}$ & $\begin{array}{l}\text { "I feel out of } \\
\text { breath" } \\
\text { "My breathing } \\
\text { requires effort" } \\
\text { "My breathing } \\
\text { requires work" } \\
\text { "I cannot get } \\
\text { enough air in" }\end{array}$ & $\begin{array}{l}\text { COPD } \\
\text { Asthma } \\
\text { Interstitial lung disease } \\
\text { Heart failure } \\
\text { Bronchiectasis } \\
\text { Deconditioning }\end{array}$ \\
\hline Exhalation & $\begin{array}{l}\text { "My breath does } \\
\text { not go out all the } \\
\text { way" }\end{array}$ & Heart failure \\
\hline Tight & $\begin{array}{l}\text { "My chest feels } \\
\text { tight" } \\
\text { "My chest is } \\
\text { constricted" }\end{array}$ & $\begin{array}{l}\text { Asthma } \\
\text { Bronchiectasis }\end{array}$ \\
\hline Inhalation & $\begin{array}{l}\text { "My breath does } \\
\text { not go all the way } \\
\text { in" }\end{array}$ & $\begin{array}{l}\text { Heart failure } \\
\text { Neuromuscular illnesses }\end{array}$ \\
\hline Rapid & $\begin{array}{l}\text { "My breathing is } \\
\text { rapid" }\end{array}$ & $\begin{array}{l}\text { Interstitial lung disease } \\
\text { Deconditioning } \\
\text { Neuromuscular illnesses }\end{array}$ \\
\hline Breathing more & $\begin{array}{l}\text { "I feel I am } \\
\text { breathing more" }\end{array}$ & Deconditioning \\
\hline Heavy & $\begin{array}{l}\text { "My breathing is } \\
\text { heavy" }\end{array}$ & $\begin{array}{l}\text { Bronchiectasis } \\
\text { Deconditioning }\end{array}$ \\
\hline Air hunger & $\begin{array}{l}\text { "I feel hunger for } \\
\text { air" }\end{array}$ & $\begin{array}{l}\text { Common description for any } \\
\text { condition as breathlessness } \\
\text { intensifies }\end{array}$ \\
\hline
\end{tabular}


clearing and post-nasal drip argue against an upper airway process causing dyspnea. Orthopnea and paroxysmal nocturnal dyspnea suggest heart failure as the cause of breathlessness.

Physical examination findings (elevated jugular venous pressure, peripheral edema) are useful in detecting heart failure as a cause of chronic dyspnea while the absence of crackles on lung exam argues against heart failure. ${ }^{21}$ Although wheezes are not specific, their absence argues against asthma or COPD as a cause of chronic dyspnea. Fine basal inspiratory crackles are suggestive of interstitial lung disease in the absence of cardiac disease.

Initial testing in the evaluation of chronic dyspnea generally includes complete blood count, blood chemistries, thyroid function tests, B-type natriuretic peptide if there is clinical suspicion of heart failure, chest X-ray, electrocardiogram, and spirometry. These studies may be sufficient to establish a working diagnosis. An algorithmic approach to the evaluation of chronic dyspnea among patients referred to a dedicated specialist clinic found that diagnoses were established in $37 \%$ of 123 patients using these studies. ${ }^{22}$ The addition of echocardiography and full pulmonary function testing (DLCO, methacholine challenge) guided by clinical suspicion improves diagnostic yield. ${ }^{23}$ Additional testing should be dictated by clinical suspicion and potentially subspecialty consultation and may include cardiopulmonary exercise testing, computed tomography of the chest, ventilation-perfusion lung scanning, and stress echocardiography. ${ }^{21,22,24}$ Table 3 provides a tiered approach to the workup of chronic breathlessness.

Before advancing to symptomatic management of refractory breathlessness, the presumed diagnosis should be carefully reconsidered if the symptom has not responded to treatment. A retrospective study of 122 patients referred to cardiology or pulmonary clinics found that diagnostic uncertainty was common. ${ }^{25}$ In addition, it is critical to assess patient understanding of illness and treatment of the underlying illness (examples: inhaler technique, medication dosing), adherence to treatment including barriers such as access to medication, and social determinants of health impacting illness (examples: housing status, health literacy, health insurance, medication costs). ${ }^{26}$

\section{SYMPTOMATIC MANAGEMENT OF BREATHLESSNESS}

In addition to diagnosing and treating the underlying causes of dyspnea, there are general principles that can guide management of this symptom. Table 4 provides a checklist of questions that guide the overall approach to breathlessness. Medical optimization and non-pharmacologic therapies provide unique benefits without the potential hazards inherent to the evidence-supported pharmacologic interventions for breathlessness. Pharmacologic options targeted at symptom relief should be considered only after other options have been exhausted.
Table 3 Tiered Workup for Chronic Breathlessness

\begin{tabular}{|c|c|c|}
\hline$\overline{\text { Tier }}$ & Components & $\begin{array}{l}\text { Diagnostic } \\
\text { considerations }\end{array}$ \\
\hline Initial & $\begin{array}{l}\text { History and physical } \\
\text { exam }\end{array}$ & $\begin{array}{l}\text { Use of findings or } \\
\text { absence of findings to } \\
\text { narrow the differential } \\
\text { and focus testing }\end{array}$ \\
\hline \multirow[t]{5}{*}{ Tier 1} & $\begin{array}{l}\text { Blood tests } \\
\text { (hemoglobin, } \\
\text { chemistries, TSH) }\end{array}$ & Anemia \\
\hline & $\begin{array}{l}\text { BNP or NT-proBNP (if } \\
\text { heart failure likely) }\end{array}$ & Heart failure \\
\hline & Chest X-ray & $\begin{array}{l}\text { Cardiopulmonary } \\
\text { processes }\end{array}$ \\
\hline & Electrocardiogram & Cardiac processes \\
\hline & Spirometry & COPD or asthma \\
\hline \multirow[t]{2}{*}{ Tier 2} & $\begin{array}{l}\text { Echocardiogram (if } \\
\text { murmur on exam or } \\
\text { suspicion of heart } \\
\text { failure) }\end{array}$ & $\begin{array}{l}\text { Heart failure } \\
\text { Cardiac valvular } \\
\text { disease } \\
\text { Pulmonary } \\
\text { hypertension }\end{array}$ \\
\hline & $\begin{array}{l}\text { Full pulmonary } \\
\text { function testing } \\
\text { (DLCO, methacholine } \\
\text { challenge) }\end{array}$ & $\begin{array}{l}\text { Asthma, COPD, } \\
\text { interstitial lung disease }\end{array}$ \\
\hline \multirow{3}{*}{$\begin{array}{l}\text { Tier } 3 \text { (guided by } \\
\text { clinical suspicion } \\
\text { and judgement) }\end{array}$} & $\begin{array}{l}\text { High resolution CT } \\
\text { chest }\end{array}$ & $\begin{array}{l}\text { Interstitial lung disease } \\
\text { Malignancy }\end{array}$ \\
\hline & $\begin{array}{l}\text { Ventilation/perfusion } \\
\text { lung scan }\end{array}$ & $\begin{array}{l}\text { Chronic } \\
\text { thromboembolic } \\
\text { disease }\end{array}$ \\
\hline & $\begin{array}{l}\text { Cardiopulmonary } \\
\text { exercise testing }\end{array}$ & $\begin{array}{l}\text { Valuable when } \\
\text { dyspnea is out of } \\
\text { proportion to the } \\
\text { known cardiac or } \\
\text { pulmonary disease } \\
\text { Helpful in supporting } \\
\text { deconditioning, } \\
\text { obesity, or psychogenic } \\
\text { cause of dyspnea }\end{array}$ \\
\hline $\begin{array}{l}\text { Subspecialty } \\
\text { consultation }\end{array}$ & $\begin{array}{l}\text { Pulmonary } \\
\text { Cardiology } \\
\text { Less commonly: } \\
\text { Gastroenterology, } \\
\text { Otolaryngology }\end{array}$ & $\begin{array}{l}\text { Can be referred at any } \\
\text { point during the } \\
\text { workup or management } \\
\text { but most value-based if } \\
\text { in conjunction with or } \\
\text { following tier } 3 \text { evalu- } \\
\text { ations }\end{array}$ \\
\hline $\begin{array}{l}\text { Response to } \\
\text { treatment }\end{array}$ & $\begin{array}{l}\text { Guideline concordant } \\
\text { treatment for the } \\
\text { presumed diagnosis or } \\
\text { diagnoses }\end{array}$ & $\begin{array}{l}\text { If inadequate response, } \\
\text { reconsider workup and } \\
\text { need for consultation. } \\
\text { Consider symptom } \\
\text { management in } \\
\text { addition to treatment of } \\
\text { the underlying disease }\end{array}$ \\
\hline
\end{tabular}

\section{MEDICAL OPTIMIZATION}

Medical optimization refers to the evaluation and treatment of the organic diseases producing breathlessness. For many patients, treating the underlying disease is sufficient for symptom resolution. However, especially for patients with acute on chronic dyspnea (i.e., acute exacerbation of severe underlying heart or lung disease), this may not provide adequate symptom control.

In addition to treating the underlying medical etiologies for dyspnea, the clinician should evaluate for psychologic triggers for worsening breathlessness. Depression and anxiety are both more common in patients with refractory dyspnea. These psychologic comorbidities can be both triggers for and sequelae of chronic breathlessness. It is not easy for patients to 
Table 4 Question Checklist for Management of Chronic Breathlessness

\section{Is the cause of breathlessness well understood?} Assess diagnostic certainty

2. Should additional tests be considered?

3. Is medical management of the underlying illness optimized? a. Guideline concordant treatment? (Example: ATS practice guideline for COPD)

b. Patient access to medications?

c. Patient understanding of treatment?

d. Patient adherence to treatment?

e. Appropriate subspecialist input?

4. What role is anxiety, depression, fear playing in symptoms?

5. How are social determinants of health impacting the underlying

illness, management, and symptoms?

6. Are there non-pharmacologic interventions that should be considered?

7. Would conditioning exercise or pulmonary rehabilitation potentially be beneficial?

8 . Is the patient a candidate for opioid-based treatment of symptoms?

9. Are there other adjuncts (example: management of anxiety or depression) that should be considered?

differentiate these components during an acute exacerbation so it is imperative that clinicians try to identify elements of this dyspnea-anxiety cycle and help patients develop approaches to control it. Patients who receive cognitive behavioral therapy-based strategies to control their symptoms have less depression, anxiety, and dyspnea, and fewer hospitalizations. ${ }^{27}$

\section{SUPPLEMENTAL OXYGEN}

Supplemental oxygen is frequently utilized in the inpatient setting. While is it clear that hypoxic patients benefit from using oxygen, ${ }^{28}$ the risk/benefit analysis for oxygen use in dyspneic (but not hypoxic) patients has evolved in recent years. Although patients may report decreased dyspnea, data suggests that it is not the supplemental oxygen, ${ }^{29}$ but rather the movement of air over the face that is helpful. ${ }^{30}$ This is important to explain as patients and caregivers often overestimate the benefits and underestimate the risks of supplemental oxygen use. $^{31}$

This becomes a particularly important distinction when we consider the potential harms of supplemental oxygen. Use of oxygen may mask evolving hypoxia and delay evaluation and treatment of the underlying cause. Oxygen use can limit patient mobility, even with portable tanks that can be taxing to carry or pull. Patients with chronic breathlessness are at higher risk for and suffer poorer outcomes from muscular deconditioning so limiting mobility is particularly detrimental. There are also the emotional hazards of utilizing supplemental oxygen. Patients can have worsened anxiety and social isolation about their illness as being connected to oxygen may be stigmatizing. ${ }^{32}$ Lastly, recent literature has shown that unnecessary oxygen use is actually associated with increased mortality as an inpatient and after discharge. ${ }^{33}$ This is in contrast to the longstanding belief that supplemental oxygen is a benign intervention. Clinicians should intentionally approach this as an education opportunity for patients and their caregivers.

\section{NON-PHARMACOLOGIC INTERVENTIONS}

Following medical optimization, first-line symptomatic therapy for breathlessness should focus on non-pharmacologic interventions. These have been widely studied and include several options that clinicians can utilize in both the inpatient and outpatient settings. The intervention with the most extensive data is pulmonary rehabilitation programs. Pulmonary rehab improves dyspnea, quality of life, and anxiety for patients with chronic breathlessness from a variety of disease processes. ${ }^{15,34,35}$ A recent retrospective cohort study of 197,376 Medicare patients admitted to the hospital with COPD exacerbations found that only $1.5 \%$ of patients initiated pulmonary rehabilitation within 90 days of discharge. ${ }^{36} \mathrm{Pul}-$ monary rehabilitation was associated with lower risk of death during the next year (absolute risk difference $-6.7 \%, 95 \%$ confidence interval -7.9 to $-5.6 \%$ ). Although hospitalists cannot provide pulmonary rehabilitation during an acute inpatient stay, data suggests they miss opportunities to refer patients. ${ }^{37}$ Outpatient physicians should also screen and refer patients with dyspnea to pulmonary rehabilitation when available.

In addition to ensuring a prescription for pulmonary rehabilitation at discharge, hospitalists can also work with nurses and/or physical therapists to ensure frequent mobility for admitted patients. Patients with chronic dyspnea are at increased risk for becoming debilitated because they limit their physical activity to avoid becoming dyspneic. Weakened muscles switch to anaerobic metabolism faster than healthy muscles and the resultant metabolic acidosis worsens breathlessness by increasing respiratory drive. ${ }^{15}$ Additionally, as patients become dyspneic, they must increase their respiratory rate to compensate. This increased respiratory rate leads to worsened respiratory mechanics with increased air trapping and respiratory muscles working beyond their functional capacity. ${ }^{15}$ It is imperative that hospitalized patients have the opportunity to maintain their baseline level of function to avoid this precipitous worsening of their dyspnea and quality of life.

A 2008 Cochrane review found that several interventions were beneficial for dyspnea including vibration of the chest wall, electrical stimulation of leg muscles, and walking aids. ${ }^{38}$ These interventions work by optimizing the balance of effort required versus work achieved. Vibration of the chest wall is thought to alter the afferent signals from mechanoreceptors in the chest wall muscles. ${ }^{39}$ Electric stimulation of leg muscles improves muscle strength and has a valuable role for patients who cannot tolerate the demands of pulmonary rehabilitation. ${ }^{40}$ Lastly, walking aids such as walkers likely improve work of breathing by encouraging a forward leaning posture and by stabilizing the rib cage which allows the chest wall muscles to more fully engage in respiratory activity. ${ }^{41}$

Additional non-pharmacologic therapies that improve breathlessness include a mixture of educational interventions and distraction techniques. Anxiety reduction techniques 
including cognitive behavioral therapy, relaxation therapy, and mindfulness exercises have been helpful. ${ }^{14,18} \mathrm{~A}$ recent meta-analysis found that Tai Chi resulted in significant improvement in dyspnea among patients with COPD. ${ }^{42}$ Breathlessness has also been improved with education on breathing techniques $^{43}$ as well as proper inhaler technique education for patients with COPD. ${ }^{44}$ There is increasing data on using music as a form of distraction. ${ }^{45}$ Lastly, there is growing data suggesting that fans directed at the face can improve symptoms without negative consequences. ${ }^{30}$

\section{PHARMACOLOGIC INTERVENTIONS}

Opioids are the primary pharmacologic option for patients who have breathlessness that is refractory to disease optimization and non-pharmacologic interventions. Opioids are believed to relieve dyspnea through several pathways including decreasing the respiratory drive, altering the central processing of dyspnea, and possibly through decreasing anxiety. ${ }^{46}$ Dyspnea and pain share neural networks so relief of both with opioids likely reflects similar mechanisms of action. Interestingly, experimental research has shown that low doses of naloxone, an opioid antagonist, increase dyspnea and decrease exercise capacity. ${ }^{47,48}$

A 2016 Cochrane review demonstrated that oral and intravenous opioids improve dyspnea, but inhaled opioids are not useful. ${ }^{49}$ Other studies have attempted to identify doses that are effective and safe in opioid-naïve patients. Safety remains a concern as opioids do carry an increased risk of mortality. ${ }^{50}$ Many physicians are reluctant to prescribe these medications because of safety concerns, as well as a lack of knowledge and experience. $^{51}$ However, low doses can be used to find a balance of safety and efficacy. A large prospective study of over 2200 patients with chronic respiratory failure found that oral morphine equivalent (OME) doses of $<30 \mathrm{mg}$ a day are safe and are not associated with increased mortality. ${ }^{50}$ As little as $10-20 \mathrm{mg}$ of OME daily may be sufficient to improve dyspnea. ${ }^{52}$ Particularly in patients dealing with life-limiting illness, clinicians should consider starting opioids for patients with refractory dyspnea in the same way we would manage refractory pain. A recent American Thoracic Society practice guideline recommended that "opioid-based therapy be considered for dyspnea management within a personalized shared decision-making approach". 53

Multiple non-opioid medications have been evaluated as potential adjuncts for dyspnea control. Buspirone has no impact on dyspnea. ${ }^{54}$ Although mirtazapine was found to reduce dyspnea, it was in a case series of six patients. ${ }^{55}$ Benzodiazepines have been used in patients with severe dyspnea but a recent Cochrane review suggests that benzodiazepines do not improve dyspnea. ${ }^{56}$ Instead, they may reduce anxiety which can be both a trigger for and a consequence of dyspnea. This must be weighed against the potential adverse effects of benzodiazepines, including an increased risk of mortality. ${ }^{50}$

\section{SUMMARY}

Clinicians routinely care for patients struggling with chronic breathlessness. Inpatient and outpatient encounters are an opportunity to develop symptom-directed plans of care beyond the routine disease-targeting therapies typically prescribed. If patients remain breathless despite medical optimization, non-pharmacologic therapies and opioids can provide significant relief. By using a systematic approach to the management of dyspnea, internists can avoid missed opportunities to recognize this often life-changing symptom while ensuring that patients benefit from the gamut of evidence-based treatment options.

Corresponding Author: Annie Massart, MD; Atlanta, USA (e-mail: Amassa2@emory.edu).

\section{Compliance with Ethical Standards:}

Conflict of Interest: Neither author has any conflict of interest to report.

\section{REFERENCES}

1. Parshall MB, Schwartzstein RM, Adams L, et al. An official American Thoracic Society statement: update on the mechanisms, assessment, and management of dyspnea. Am J Respir Crit Care Med. 2012;185(4):435452.

2. Stevens JP, Sheridan AR, Bernstein HB, et al. A Multidimensional Profile of Dyspnea in Hospitalized Patients. Chest. 2019;156(3):507-517.

3. Smith AK, Currow DC, Abernethy AP, et al. Prevalence and Outcomes of Breathlessness in Older Adults: A National Population Study. J Am Geriatr Soc. 2016;64(10):2035-2041

4. Bowden JA, To TH, Abernethy AP, Currow DC. Predictors of chronic breathlessness: a large population study. BMC Public Health. 2011;11:33.

5. Currow DC, Plummer JL, Crockett A, Abernethy AP. A community population survey of prevalence and severity of dyspnea in adults. J Pain Symptom Manage. 2009;38(4):533-545.

6. Carette H, Zysman M, Morelot-Panzini C, et al. Prevalence and management of chronic breathlessness in COPD in a tertiary care center. BMC Pulm Med. 2019;19(1):95.

7. Ho SF, O'Mahony MS, Steward JA, Breay P, Buchalter M, Burr ML Dyspnoea and quality of life in older people at home. Age Ageing. 2001;30(2):155-159.

8. Edmonds $\mathbf{P}$, Karlsen S, Khan S, Addington-Hall J. A comparison of the palliative care needs of patients dying from chronic respiratory diseases and lung cancer. Palliat Med. 2001;15(4):287-295.

9. Mahler DA, O'Donnell DE. Recent advances in dyspnea. Chest. 2015; 147(1):232-241.

10. Hayes AW, Philip J, Spruyt OW. Patient reporting and doctor recognition of dyspnoea in a comprehensive cancer centre. Intern Med J. 2006;36(6):381-384.

11. Gruenberger JB, Vietri J, Keininger DL, Mahler DA. Greater dyspnea is associated with lower health-related quality of life among European patients with COPD. Int $\mathrm{J}$ Chron Obstruct Pulmon Dis. 2017;12:937944.

12. O'Donnell DE, James MD, Milne KM, Neder JA. The Pathophysiology of Dyspnea and Exercise Intolerance in Chronic Obstructive Pulmonary Disease. Clin Chest Med. 2019;40(2):343-366.

13. Edmonds P, Higginson I, Altmann D, Sen-Gupta G, McDonnell M. Is the presence of dyspnea a risk factor for morbidity in cancer patients? J Pain Symptom Manage. 2000;19(1):15-22.

14. Yohannes AM, Junkes-Cunha M, Smith J, Vestbo J. Management of Dyspnea and Anxiety in Chronic Obstructive Pulmonary Disease: A Critical Review. J Am Med Dir Assoc. 2017;18(12):1096 e1091-1096 e1017. 
15. O'Donnell DE, Milne KM, James MD, de Torres JP, Neder JA. Dyspnea in COPD: New Mechanistic Insights and Management Implications. Adv Ther. 2020;37(1):41-60.

16. Stoeckel MC, Esser RW, Gamer M, Buchel C, von Leupoldt A. Brain Responses during the Anticipation of Dyspnea. Neural Plast. 2016;2016:6434987.

17. De Peuter S, Van Diest I, Lemaigre V, Verleden G, Demedts M, Van den Bergh O. Dyspnea: the role of psychological processes. Clin Psychol Rev. 2004;24(5):557-581.

18. Lok CW. Management of Breathlessness in Patients With Advanced Cancer: A Narrative Review. Am J Hosp Palliat Care. 2016;33(3):286-290.

19. Mahler DA, Harver A, Lentine T, Scott JA, Beck K, Schwartzstein RM. Descriptors of breathlessness in cardiorespiratory diseases. Am J Respir Crit Care Med. 1996;154(5):1357-1363.

20. Chang AS, Munson J, Gifford AH, Mahler DA. Prospective use of descriptors of dyspnea to diagnose common respiratory diseases. Chest. 2015; 148(4):895-902.

21. Ferry OR, Huang YC, Masel PJ, et al. Diagnostic approach to chronic dyspnoea in adults. J Thorac Dis. 2019;11(Suppl 17):S2117-S2128.

22. Pratter MR, Abouzgheib W, Akers S, Kass J, Bartter T. An algorithmic approach to chronic dyspnea. Respir Med. 2011;105(7):1014-1021.

23. Pedersen F, Mehlsen J, Raymond I, Atar D, Skjoldborg US, Hildebrandt PR. Evaluation of dyspnoea in a sample of elderly subjects recruited from general practice. Int J Clin Pract. 2007;61(9):1481-1491.

24. Brenner S, Guder G. The patient with dyspnea. Rational diagnostic evaluation. Herz. 2014;39(1):8-14

25. Huang YC, Ferry OR, McKenzie SC, et al. Diagnosis of the cause of chronic dyspnoea in primary and tertiary care: characterizing diagnostic confidence. J Thorac Dis. 2018;10(6):3745-3756.

26. Byhoff E, Kangovi S, Berkowitz SA, et al. A Society of General Internal Medicine Position Statement on the Internists' Role in Social Determinants of Health. J Gen Intern Med. 2020;35(9):2721-2727.

27. Howard C, Dupont S. 'The COPD breathlessness manual': a randomised controlled trial to test a cognitive-behavioural manual versus information booklets on health service use, mood and health status, in patients with chronic obstructive pulmonary disease. NPJ Prim Care Respir Med. 2014;24:14076.

28. Continuous or nocturnal oxygen therapy in hypoxemic chronic obstructive lung disease: a clinical trial. Nocturnal Oxygen Therapy Trial Group. Ann Intern Med. 1980;93(3):391-398.

29. Abernethy AP, McDonald CF, Frith PA, et al. Effect of palliative oxygen versus room air in relief of breathlessness in patients with refractory dyspnoea: a double-blind, randomised controlled trial. Lancet. 2010;376(9743):784-793.

30. Gian Y, Wu Y, Rozman de Moraes A, et al. Fan Therapy for the Treatment of Dyspnea in Adults: A Systematic Review. J Pain Symptom Manage. 2019;58(3):481-486.

31. Collier A, Breaden K, Phillips JL, Agar M, Litster C, Currow DC. Caregivers' Perspectives on the Use of Long-Term Oxygen Therapy for the Treatment of Refractory Breathlessness: A Qualitative Study. J Pain Symptom Manage. 2017;53(1):33-39.

32. Khor YH, Goh NSL, McDonald CF, Holland AE. Oxygen Therapy for Interstitial Lung Disease. A Mismatch between Patient Expectations and Experiences. Ann Am Thorac Soc. 2017;14(6):888-895.

33. Chu DK, Kim LH, Young PJ, et al. Mortality and morbidity in acutely ill adults treated with liberal versus conservative oxygen therapy (IOTA): a systematic review and meta-analysis. Lancet. 2018;391(10131):16931705

34. Faverio P, De Giacomi F, Bonaiti G, et al. Management of Chronic Respiratory Failure in Interstitial Lung Diseases: Overview and Clinical Insights. Int J Med Sci. 2019; 16(7):967-980.

35. Quinn C, Wisse A, Manns ST. Clinical course and management of idiopathic pulmonary fibrosis. Multidiscip Respir Med. 2019;14:35

36. Lindenauer PK, Stefan MS, Pekow PS, et al. Association Between Initiation of Pulmonary Rehabilitation After Hospitalization for COPD and 1-Year Survival Among Medicare Beneficiaries. JAMA. 2020;323(18): 1813-1823.

37. Kochovska S, Fazekas B, Hensley M, Wheatley J, Allcroft P, Currow DC. A Randomized, Double-Blind, Multisite, Pilot, Placebo-Controlled
Trial of Regular, Low-Dose Morphine on Outcomes of Pulmonary Rehabilitation in COPD. J Pain Symptom Manage. 2019;58(5):e7-e9.

38. Bausewein C, Booth S, Gysels M, Higginson I. Non-pharmacological interventions for breathlessness in advanced stages of malignant and non-malignant diseases. Cochrane Database Syst Rev. 2008(2):CD005623.

39. Sibuya M, Yamada M, Kanamaru A, et al. Effect of chest wall vibration on dyspnea in patients with chronic respiratory disease. Am J Respir Crit Care Med. 1994;149(5):1235-1240.

40. Gong H, Jiang $\mathbf{Q}$, Shen $\mathbf{D}$, Gao J. Neuromuscular electrical stimulation improves exercise capacity in adult patients with chronic lung disease: a meta-analysis of English studies. J Thorac Dis. 2018;10(12):6722-6732.

41. Marciniuk DD, Goodridge D, Hernandez $\mathbf{P}$, et al. Managing dyspnea in patients with advanced chronic obstructive pulmonary disease: a Canadian Thoracic Society clinical practice guideline. Can Respir J. 2011;18(2):69-78.

42. Easwaran K, Gopalasingam Y, Green DD, et al. Effectiveness of Tai Chi for health promotion for adults with health conditions: a scoping review of Meta-analyses. Disabil Rehabil. 2020:1-12.

43. Valenza MC, Valenza-Pena G, Torres-Sanchez I, Gonzalez-Jimenez E, Conde-Valero A, Valenza-Demet G. Effectiveness of controlled breathing techniques on anxiety and depression in hospitalized patients with COPD: a randomized clinical Trial. Respir Care. 2014;59(2):209-215.

44. Ozoglu Aytac S, Kilic SP, Ovayolu N. Effect of inhaler drug education on fatigue, dyspnea severity, and respiratory function tests in patients with COPD. Patient Educ Couns. 2020;103(4):709-716.

45. Lee AL, Dolmage TE, Rhim M, Goldstein RS, Brooks D. The Impact of Listening to Music During a High-Intensity Exercise Endurance Test in People With COPD. Chest. 2018;153(5):1134-1141.

46. Mahler DA. Opioids for refractory dyspnea. Expert Rev Respir Med. 2013;7(2):123-134; quiz 135

47. Gifford AH, Mahler DA, Waterman LA, et al. Neuromodulatory effect of endogenous opioids on the intensity and unpleasantness of breathlessness during resistive load breathing in COPD. COPD. 2011;8(3):160-166.

48. Mahler DA, Murray JA, Waterman LA, et al. Endogenous opioids modify dyspnoea during treadmill exercise in patients with COPD. Eur Respir J. 2009;33(4):77 1-777.

49. Barnes H, McDonald J, Smallwood N, Manser R. Opioids for the palliation of refractory breathlessness in adults with advanced disease and terminal illness. Cochrane Database Syst Rev. 2016;3:CD011008.

50. Ekstrom MP, Bornefalk-Hermansson A, Abernethy AP, Currow DC. Safety of benzodiazepines and opioids in very severe respiratory disease: national prospective study. BMJ. 2014;348:g445.

51. Rocker G, Young J, Donahue M, Farquhar M, Simpson C. Perspectives of patients, family caregivers and physicians about the use of opioids for refractory dyspnea in advanced chronic obstructive pulmonary disease. CMAJ. 2012;184(9):E497-504

52. Currow DC, McDonald C, Oaten S, et al. Once-daily opioids for chronic dyspnea: a dose increment and pharmacovigilance study. J Pain Symptom Manage. 2011;42(3):388-399.

53. Nici L, Mammen MJ, Charbek E, et al. Pharmacologic Management of Chronic Obstructive Pulmonary Disease. An Official American Thoracic Society Clinical Practice Guideline. Am J Respir Crit Care Med. 2020;201(9):e56-e69.

54. Peoples AR, Bushunow PW, Garland SN, et al. Buspirone for management of dyspnea in cancer patients receiving chemotherapy: a randomized placebo-controlled URCC CCOP study. Support Care Cancer. 2016;24(3): 1339-1347.

55. Lovell N, Bajwah S, Maddocks M, Wilcock A, Higginson IJ. Use of mirtazapine in patients with chronic breathlessness: A case series. Palliat Med. 2018;32(9): 1518-1521.

56. Simon ST, Higginson IJ, Booth S, Harding $\mathbf{R}$, Weingartner V, Bausewein C. Benzodiazepines for the relief of breathlessness in advanced malignant and non-malignant diseases in adults. Cochrane Database Syst Rev. 2016;10:CD007354.

Publisher's Note: Springer Nature remains neutral with regard to jurisdictional claims in published maps and institutional affiliations. 